\title{
Update on the bird-egg syndrome and genuine poultry meat allergy
}

Wolfgang Hemmer', Christoph Klug ${ }^{2}$, Ines Swoboda ${ }^{2}$

${ }^{1}$ Floridsdorf Allergy Centre, Vienna, Austria, ${ }^{2}$ Molecular Biotechnology Section, University of Applied Sciences, Campus Vienna Biocenter, Vienna, Austria

Key words poultry meat allergy - chicken meat allergy bird-eggsyndrome serum albumin a-parvalbumin myosin light chain

\section{Submitted}

July 7, 2015

Accepted August 22, 2015

German version www.springermedizin.de/ allergo-journal

\section{Summary}

Allergy to poultry meat is rare and affects both children and adults. The prevalence of poultry meat allergy is unknown, but presumably is similar to that of red meat allergy. There is no close relationship between allergy to poultry meat and allergy to red meat. Poultry meat allergy may present as primary (genuine) food allergy or as secondary food allergy resulting from cross-reactivity.

Secondary poultry meat allergy may arise in the context of bird-egg-syndrome, which is due to sensitization to serum albumins present in many tissues including muscle tissue and egg yolk (Gal d 5). Primary sensitization to serum albumin may happen via the respiratory tract through exposure to pet birds (mainly in adults) or within the context of egg allergy in early childhood. Due to the heat lability of serum albumins, reactions are often limited to the skin upon contact with raw meat. Symptoms from meat ingestion are rare and mostly mild, whereas systemic reactions are common after ingestion of raw or soft-boiled egg yolk.

Primary poultry meat allergy is mainly seen in adolescents and young adults, though hypersensitivity may have started already at (pre)school age. Egg allergy is usually absent. Typical symptoms of primary poultry meat allergy include OAS ( \pm dyspnea), gastrointestinal complaints, urticaria and an- gioedema. Severe anaphylaxis with cardiovascular symptoms is rare. Chicken and turkey meat are highly cross-reactive and responsible for most reactions, while duck and goose meat causes milder or no symptoms. Soups, sausages, and ham represent relevant allergen sources, too. Patients with poultry meat allergy unexpectedly often suffer from concomitant allergy to fish and possibly shrimp. Serum specific IgE against fish and shrimp is found in respectively 60 and $40 \%$ of sera, suggestive of cross-reactive allergens in these foods. The allergens thus far recognized in genuine poultry meat are LMW proteins of 5-25 kDa. One of them has been identified as a-parvalbumin cross-reactive with homologous mammal a-parvalbumins but not with fish a-parvalbumins. Recently, myosin light chains, including $23 \mathrm{kDa}$ MLC-1 (Gal d 7) and $15 \mathrm{kDa}$ MLC-3, have been recognized as new major allergens in chicken meat. The high similarity of chicken MLCs with those from various fish species ( 65\%) might explain the clinical association of poultry meat allergy with fish allergy.

Cite this as Hemmer W, Klug C, Swoboda I. Update on the bird-egg syndrome and genuine poultry meat allergy. Allergo J Int 2016;25:68-75

DOI: $10.1007 / \mathrm{s} 40629-016-0102-8$

\section{Introduction}

Food allergy to poultry meat is rare just as allergy to red meat [1]. Published data on poultry meat allergy mainly refer to single case reports and small case series, reliable data on the prevalence of clinical poultry meat allergy are not available. In certain patient subgroups, such as children with atopic dermatitis, sensitization to chicken meat may be encountered in up to $20 \%$ [2]. However, this is rarely clinically relevant and probably mostly due to cross-sensitization in subjects with egg allergy. Overall, allergic reactions to poultry meat might be 
as common as reactions to red meat. Yet, following the recent discovery of alpha-galactose $(\alpha-\mathrm{Gal})$ as a novel $\operatorname{IgE}$ epitope in red meat, work published within the last couple of years is conspicuously dominated by papers dealing with $\alpha-\mathrm{Gal}$.

Though in some cases an immunologic linkage may exist between poultry meat and red meat allergy, hypersensitivity to these two types of meat basically represents two distinct entities. Within cases of poultry meat allergy again, two different types may be distinguished depending on the sensitization route and the allergens involved:

1. Primary (genuine) poultry meat allergy, resulting from active sensitization through heat-resistant meat allergens via the intestinal mucosa. There is no causal relationship with egg allergy.

2. Secondary poultry meat allergy, which is due to sensitization to ubiquitous serum albumins and which is closely associated with allergy to hen's egg. Primary sensitization to serum albumins may have either occurred via the respiratory route through exposure to birds (bird-egg syndrome), or, in children, may be due to primary sensitization to egg yolk (egg-bird syndrome). Secondary poultry meat allergy in the context of bird-egg syndrome matches the situation in cat-pork syndrome, which in analogy is based on primary inhalant sensitization to mammalian serum albumins through exposure to furry animals.

\section{Poultry meat allergy in bird-egg syndrome}

The very first reports on poultry meat allergy refer to patients with bird-egg syndrome $[3,4]$. Bird-egg syndrome is mainly seen in adults who became sensitized to airborne avian allergens through exposure to feathers and droppings of pet birds (mostly budgerigars, less often canary birds and parrots) $[5,6,7]$. Bird-egg syndrome is uncommon in children [8].

The responsible allergens in the bird-egg syndrome have early been identified as serum albumins $[3,5,6,9,10]$. Serum albumins are highly cross-reactive proteins conserved in amino acid sequence and protein structure with a molecular weight around $70 \mathrm{kDa}$. They can be found in all tissues, in cluding muscle tissue, as well as in high amounts in

\begin{tabular}{ll}
\multicolumn{2}{l}{ Abbrevations } \\
a-Gal & Alpha-galactose \\
ELISA & Enzyme-linked immunosorbent assay \\
IgE & Immunglobulin E \\
MLC-1 & Myosin light chain 1 \\
SDS-PAGE & $\begin{array}{l}\text { Sodium dodecylsulfate polyacryl- } \\
\text { amide gel electrophoresis }\end{array}$
\end{tabular}

egg yolk (= a-livetin, Gal d 5). On allergy testing, simultaneous reactivity with bird feathers, egg yolk, and chicken meat is regularly seen in vivo as well as in vitro [6]. Strong reciprocal cross-inhibition was shown between extracts from bird feathers and egg yolk, but not with egg white [6]. IgE scores in patients with bird-egg syndrome are typically highest with bird feathers, intermediate with egg yolk, and lowest with chicken meat $[6,8]$.

Due to the cross-reactivity between different avian serum albumins, patients may develop allergic symptoms after ingestion of raw or soft-boiled egg yolk, including oral and gastro-intestinal symptoms as well as mild to moderately severe systemic reactions (urticaria, angioedema, asthma) $[3,4,5,6,9$, 10]. Due to the heat lability of serum albumins [9], hard-boiled egg yolk is well tolerated. Different from classic early-childhood egg allergy, egg allergy within the bird-egg syndrome is typically late-onset, characterized by isolated or dominating sensitization to egg-yolk, and mostly persisting $[9,11]$.

Even if most patients with bird-egg syndrome are positive to chicken meat on skin testing and in vitro testing, allergic reactions after meat consumption are rare and usually mild (e. g., oral allergy syndrome). Studies in children and adults double-positive to egg yolk and bird feathers revealed meat intolerance in $22 \%$ and $12 \%$ of subjects, respectively $[4,12]$. The main reason for the infrequence of clinical symptoms is the limited heat resistance of serum albumins and the fact that poultry meat is essentially consumed only well-done [9]. Instead, local reactions (itch, erythema, contact urticaria) upon contact with raw meat are commonly seen. In case of ingestion of incompletely cooked meat systemic reaction may occasionally occur $[4,13]$.

Not all cases described as bird-egg syndrome are genuine cases of bird-egg syndrome. Children with primary allergy to egg-yolk regularly show positive allergy test results also for chicken meat and bird feathers, however, sensitization to chicken serum albumin (Gal d 5) originated from intestinal exposure to egg yolk but not from exposure to pet birds ("egg-bird syndrome") $[11,13,14]$. Most of these children also suffer from allergy to egg-white. Subsequent exposure to pet birds may induce respiratory symptoms in these patients [13].

\section{Genuine (primary) poultry meat allergy}

Primary poultry meat allergy stands for a true type 1 food allergy with genuine sensitization to presumably heat-stable meat allergens and without a causal relationship to concomitant egg and bird feather sensitization. Specific studies on the prevalence of genuine poultry meat allergy do not exist. The majority of published work refers to case reports (Tab. 1). 


\section{Onset and clinical characteristics}

Primary poultry meat allergy has been described mainly in young adults, even if first symptoms were often recognized by patients already in childhood (Tab. 1). In an ongoing study at our centre we identified 28 patients with a history of genuine poultry meat allergy confirmed by positive skin test and/or specific IgE against chicken meat (mean $3.95 \pm$ $7.33 \mathrm{kU} / \mathrm{l}$, range $0.17-35.9)$. In consistency with published data, most of our patients were adolescents and young adults, and less often infants (Fig. 1). However, according to case histories meat intolerance started already at preschool and school age in many subjects (median: $10 \mathrm{yrs}$ ). Anyhow, in around $20 \%$ meat intolerance started only after the age of 20 . Hence, genuine poultry meat allergy holds an interesting intermediate position with regard to disease onset, starting clearly later than typical early-childhood food allergies (such as milk, egg, and wheat), but mostly earlier than allergies against red meat caused by serum albumins or $\alpha-G a l$.

The range of symptoms associated with genuine poultry allergy include contact reactions, oral allergy syndrome (which is often severe and associated with breathing difficulties) and regularly systemic reactions, which, however, are mostly moderate in severity and confined to the skin and the gastro-intestinal tract (urticaria, angioedema, nausea, emesis, diarrhea, asthma) (Fig. 2). Severe anaphylaxis with cardiovascular symptoms appears to be uncommon. Different from $\alpha$-Gal-mediated allergy to red meat, reactions to poultry meat usually start within 30 minutes as typical for type 1 food allergies.

\section{Culprit foods}

Chicken meat is the most common elicitor of allergic reactions. Turkey meat is highly cross-reactive and thus most patients react comparably also to turkey meat $[17,18,21,27]$. Allergy testing nearly always reveals double-positive results to both birds. Symptoms may also develop after meat consumption from goose, duck, peasant, and other birds, but symptoms are usually milder or these foods are even well-tolerated $[18,20]$.

Also soups as well as sausages and ham prepared from turkey meat have to be considered relevant triggers of allergic reactions [17, 21, 28]. Prick-toPrick tests with native meat and meat products in our own patients regularly provoked equivalent test reactions to chicken meat, turkey meat, turkey ham and salami. Anaphylaxis from unexpected "hidden" poultry meat allergens due to the growing replacement of pork ham by turkey ham has been described [17]. Like in fish allergy, even exposure to cooking steams may cause allergic reactions in highly sensitive subjects $[26,29]$.

\begin{tabular}{|c|c|c|c|c|c|}
\hline Author & $\mathbf{n}$ & Age (yrs) & Onset (yrs) & $\begin{array}{l}\text { Reported symptoms after } \\
\text { ingestion of poultry meat }\end{array}$ & Other food allergies \\
\hline Liccardi et al. 1997 [15] & 1 & 23 & $3 ?$ & $\mathrm{U}, \mathrm{AE}, \mathrm{A}$ & \\
\hline Vila et al. 1998 [16] & 1 & 21 & $?$ & OAS & \\
\hline Cahen et al. 1998 [17] & 2 & 10,25 & childhood & OAS, U, N, V & \\
\hline Kelso et al. 1999 [18] & 3 & $18-19$ & $?$ & OAS, A, U & \\
\hline Zacharisen 2006 [19] & 1 & 41 & $?$ & $\mathrm{Gl}, \mathrm{U}, \mathrm{A}$ & \\
\hline Sokolova et al. 2009 [20] & 1 & 31 & 29 & OAS, PR, E & \\
\hline Kuehn et al. 2009 [21] & 1 & 54 & $?$ & OAS, V, HYPO & fish \\
\hline Theler et al. 2009 [22] & $1^{*}$ & 28 & $?$ & $\mathrm{OAS}, \mathrm{RC}, \mathrm{AE}, \mathrm{U}, \mathrm{V}$ & \\
\hline Hilger et al. 2010 [23] & 1 & 42 & $?$ & $\mathrm{RC}, \mathrm{A}$ & pork \\
\hline Gonzalez-Mancebo et al. 2011 [24] & 1 & 20 & $?$ & $\mathrm{OAS}, \mathrm{U}, \mathrm{AE}, \mathrm{A}$ & \\
\hline Gonzales-de-Olano et al. 2012 [25] & 1 & 23 & $?$ & A & fish \\
\hline Barnig et al. 2012 [26] & 1 & 16 & 14 & OAS, Gl; A from cooking steams & \\
\hline Can et al. 2014 [27] & 1 & 13 & 7 & $\mathrm{OAS}, \mathrm{E}, \mathrm{AE}, \mathrm{RC}$ & \\
\hline
\end{tabular}




\section{Allergens in poultry meat}

The allergenic molecules involved in genuine poultry meat allergy are not yet well known. First immunoblot studies based on a limited number of patients indicated that IgE antibodies from allergic subjects mainly bind with low molecular weight proteins between 5 and $25 \mathrm{kDa}[15,17,18]$. In addition, these studies revealed a high degree of crossreactivity between the low molecular weight allergens in extracts from chicken and turkey meat [17]. Muscle a-parvalbumin was the very first protein identified in a patient as a relevant chicken meat allergen [21]. The patient's IgE also bound to the a-parvalbumins from turkey, cow, horse, and frog, suggesting cross-reactivity between the $\alpha$-parvalbumins from all these species. No reactivity was yet observed with $\beta$-parvalbumins, the major allergens from fishes [21]. A subsequent case study confirmed a-parvalbumin as an important allergen in chicken meat and in addition could identify the muscle protein myosin light chain 1 as another relevant allergen [24].

\section{Myosin light chain 1: a new major allergen in poultry meat}

Our own studies on more than 20 patients represent the first performed in large patient populations. By using IgE immunoblotting and subsequent identification of IgE-reactive proteins by peptide mass fingerprinting, we could identify myosin light chain 1 (MLC-1) as an allergen recognized by the majority of patients (Fig. 3) [30].

Myosin light chains together with myosin heavy chains make up the subunits of the motor protein myosin [31], which, in concert with actin, triggers contraction of muscle fibers. MLCs are small proteins comprising several isoforms with a molecular weight of $16-24 \mathrm{kDa}$ [31]. Our own immunoblot experiments followed by mass spectrometry revealed that, apart from MLC-1 (Gal d 7; $23 \mathrm{kDa}$ ), also MLC-3 ( 15 kDa), a truncated isoform of MLC-1 derived from the same gene by alternative transcription and splicing and deviating from MLC-1 just by few amino acids [31], is recognized by patients' IgE. cDNA cloning of chicken MLC-1 and production as a recombinant protein made possible a more comprehensive characterization of the allergen by ELISA (enzyme-linked immunosorbent assay) and IgE inhibition experiments. The results confirmed MLC-1 as a markedly heat-stable major allergen in chicken meat strongly cross-reactive with homologous proteins from turkey, goose, and duck [30].

\section{Egg sensitization and genuine poultry meat allergy}

In contrast to poultry meat intolerance within the frame of the bird-egg syndrome, genuine poultry

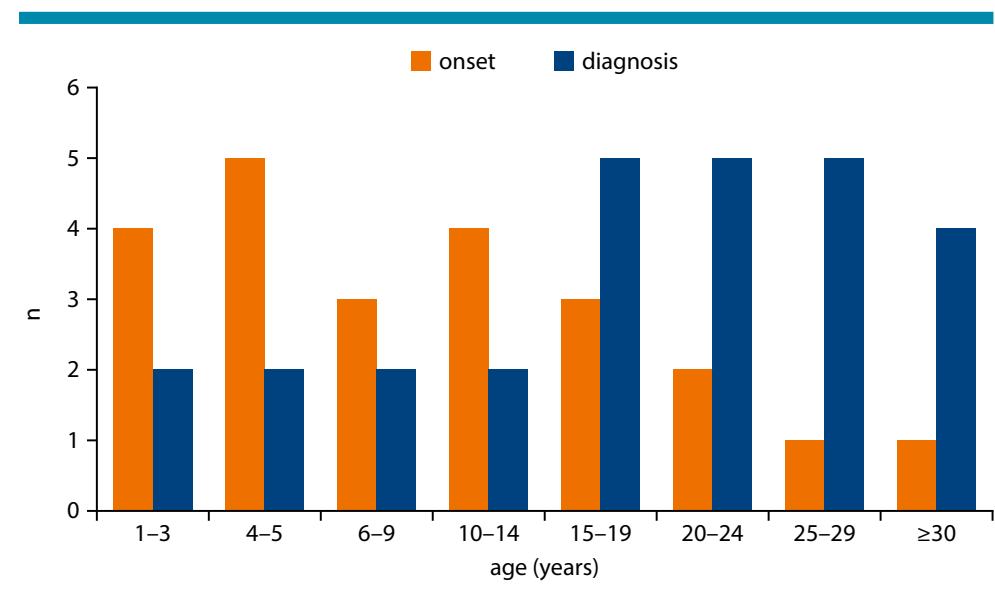

Fig. 1: Primary chicken meat allergy: onset of hypersensitivity according to medical history and age when allergy was diagnosed $(n=23)$

meat allergy is considered to have no causal relationship with sensitization to egg and bird feathers. Accordingly, virtually all published reports on genuine poultry meat allergy unequivocally describe the absence of egg intolerance in patients along with negative allergy test results to egg white and egg yolk.

Surprisingly and contrasting with published data, we did observe a weak co-sensitization to egg white and/or egg yolk in many of our patients, even if most of them did not suffer from clinical egg intolerance. As much as $66 \%$ of patients had serum $\operatorname{IgE}$ antibody levels $\geq 0.35 \mathrm{kU} / \mathrm{l}$ against egg white and/or egg yolk, however, these IgE values were always much low than those for chicken meat (Fig. 4). It remains to be elucidated how and whether this egg-specific IgE reactivity is causally linked up with chicken meat allergy. In some patients

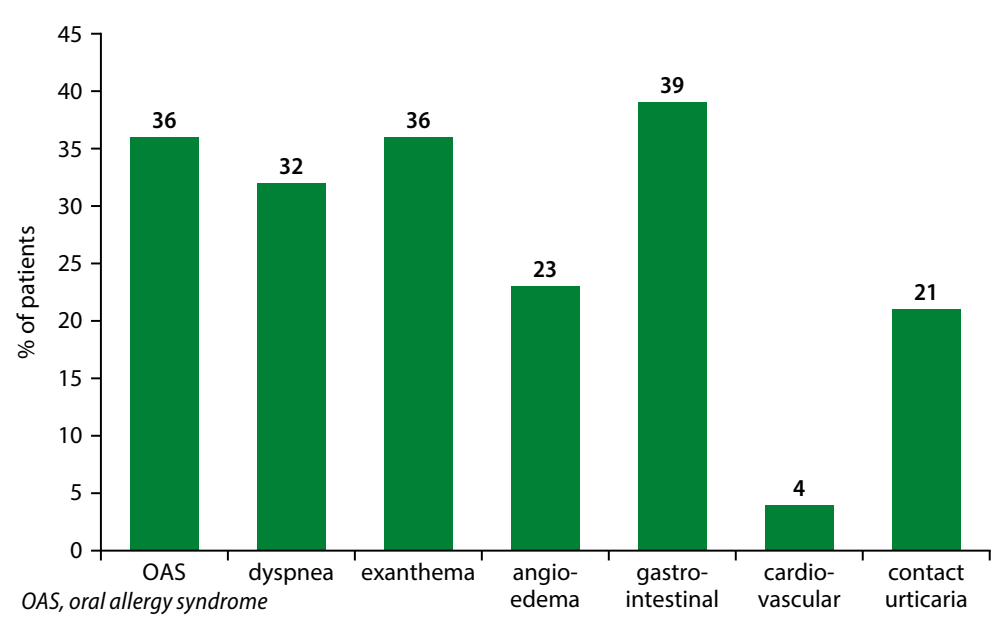

Fig. 2: Frequency of symptoms in 28 patients with genuine poultry meat allergy 


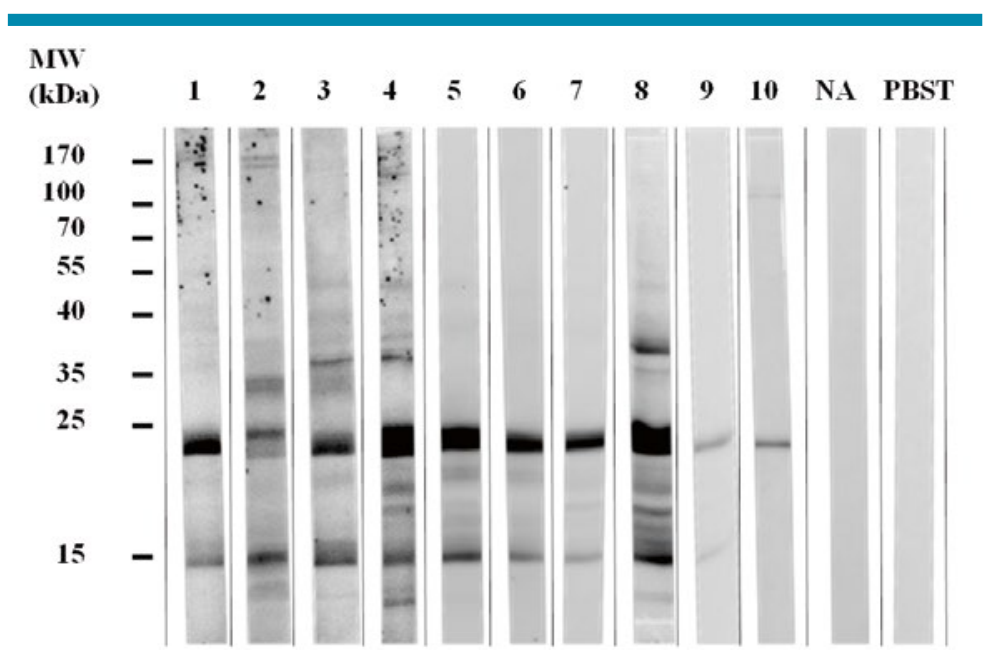

MW, molecular weight; NA, non-allergic control serum; PBST, buffer control

Fig. 3: IgE binding to myosin light chain isoforms. Proteins from boiled chicken meat were separated by SDS-PAGE (sodium dodecylsulfate polyacrylamide gel electrophoresis), blotted onto nitrocellulose membranes and incubated with sera from 10 chicken meat-allergic patients. Proteins of $23 \mathrm{kDa}$ and 15 $\mathrm{kDa}$ recognized by patients' IgE were analyzed by peptide mass fingerprinting and identified as myosin light chain 1 and myosin light chain 3, respectively.

with atopic background, it might represent remnants of early-childhood egg allergy independent of meat allergy, but this is unlikely a satisfying explanation for all patients. Inhibition experiments using meat extracts in a limited number of patients thus far failed to show a specific cross-reactivity between allergens in egg white/egg yolk and chicken meat.

\section{Relationships with red meat allergy}

Usually, poultry meat allergy and red meat allergy are not associated with one another. Simultaneous intolerance to both types of meat is uncommon but does occur. Taking into account the infrequence of meat allergies, such double-sensitivity might be more likely due to cross-reactivity than true double-sensitization.

Ayuso et al. studied 57 patients with allergic reactions to either red or poultry meat by dot blot and observed double-positive test results to mammal and poultry meat in as much as $35 \%$ of subjects [28]. However, the specificity of the blotting method used might have been limited and no further characterization of potential cross-reactive allergens has been performed making the significance of these observations uncertain.

Hilger et al. described a patient with occupationrelated pork allergy who later also developed severe oral allergy syndrome, rhino-conjunctivitis, and breathing difficulties after ingestion of chicken meat [23]. By using immunoblotting and inhibition experiments, the authors could show that the patient was cross-sensitized to porcine and chicken hemoglobin a-chain, which have a sequence identity of $57 \%$. In addition, the patient also had IgE antibodies to pig serum albumin which cross-reacted with chicken serum albumin. Anyhow, cross-reactivity between mammal and avian serum albumins, which have sequence identities of only $\sim 45 \%$, appears to be uncommon [32]. This matches our own observations. Among our own patients with chicken meat allergy, $7 \%(2 / 28)$ reported concurrent hypersensitivity to red meat which was supported by double-positive test

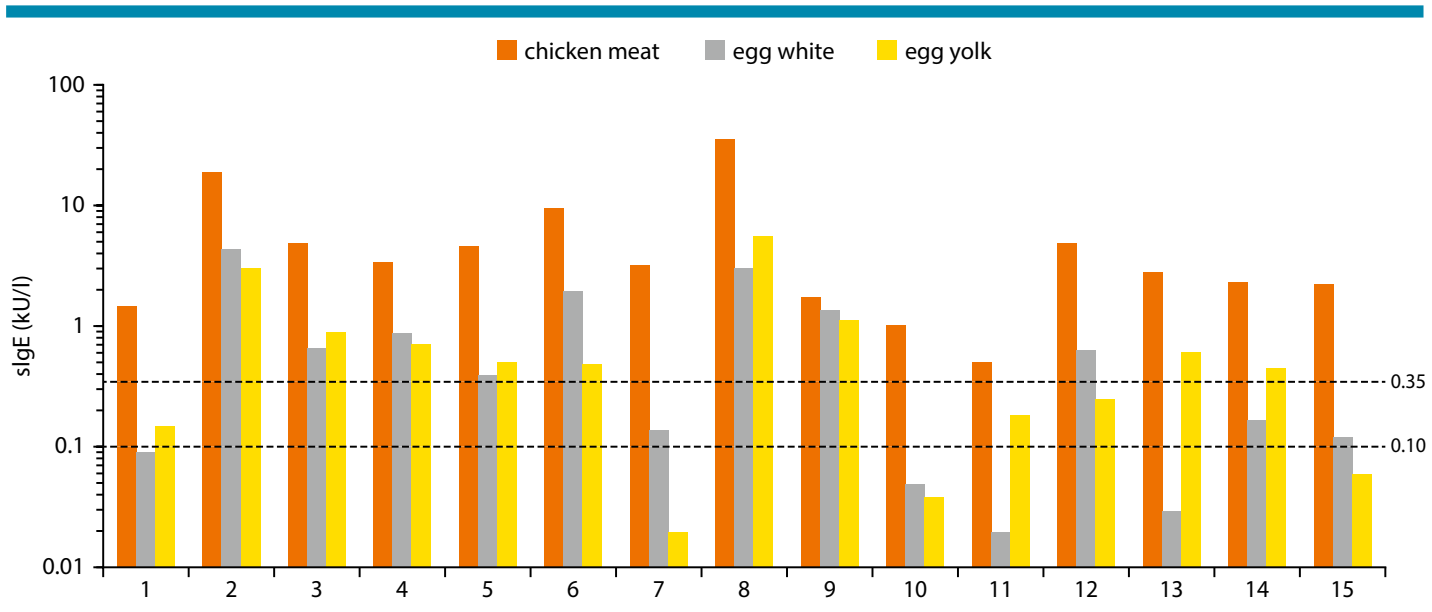

$\operatorname{slg} E$, specific $\lg E$

Fig. 4: ImmunoCAP IgE binding to chicken meat, hen's egg white and hen's egg yolk in 15 patients with genuine chicken meat allergy. $67 \%$ of patients (10/15) showed low-level lgE binding $>0.35 \mathrm{kU} / \mathrm{l}$ to egg white and/or egg yolk. 
results to both types of meat. Whatever the responsible allergens in these cases are, both patients were not sensitized to serum albumins anyway.

Another muscle protein potentially connecting allergy to poultry and red meat is a-parvalbumin, which shows a high degree of homology ( 80\%) between birds and mammals. Cross-reactivity has been demonstrated in vitro between recombinant a-parvalbumins from chicken, turkey, cow, horse, and frog [21], but the clinical relevance of this cross-reactivity is still unknown.

\section{"Fish-shrimp-meat syndrome": polyvalent food allergy?}

Allergy to fish and shrimp basically represent distinct entities mediated by completely different allergenic proteins. Beta-parvalbumins are the principal major allergens in fish allergy [33], whereas the most important allergens in shrimp allergy are tropomyosins (Pen $\mathrm{m} \mathrm{1}$ ) and to a lesser extent arginine kinase (Pen $\mathrm{m} \mathrm{2}$ ) and sarcoplasmatic Ca-binding protein (Pen $\mathrm{m} 4$ ) $[34,35]$. The examination of our own patients with poultry meat allergy $(n=28)$ unexpectedly provided strong evidence for a potentially close relationship with fish allergy and possibly also shrimp allergy.

Actually, at least $30 \%$ of patients reported concomitant fish allergy, and of 19 investigated sera $63 \%$ had specific IgE levels > $0.35 \mathrm{kU} / \mathrm{l}$ (mean 1.31 $\pm 1.80 \mathrm{kU} / \mathrm{l}$, range $0.07-7.23)$ against cod (most of them being negative for recombinant cod parvalbu$\min \mathrm{rGad} c 1$ ) and $42 \%$ against shrimp (mean 2.43 $\pm 6.61 \mathrm{kU} / \mathrm{l}$, range $0.03-27.5$ ). Co-sensitization to fish and/or shrimp can be often confirmed by skin testing (Fig. 5). Considering specific IgE-levels in these patients, the primary sensitizer indeed might have been fish or shellfish but not poultry meat in $25 \%$ of patients, since the IgE scores to these foods were markedly higher than those to poultry meat itself.

Concomitant fish allergy in poultry meat-allergic patients has been already described in two case reports where $\alpha$-parvalbumin was identified as the responsible meat allergen $[21,25]$. In one of these reports specific cross-reactivity between poultry meat and fish extracts was proven, presumably based on cross-reactivity between chicken $\alpha$-parvalbumin and fish $\beta$-parvalbumin [25], whereas in the other study no such cross-reactivity could be observed [21]. Anyhow, that simultaneous allergy to poultry meat and fish (and perhaps shrimp) might be widespread and be based on cross-reactive allergens in these foods has thus far not yet been anticipated.

Apart from parvalbumins further and perhaps even more important cross-reactive allergens might exist in poultry meat, fish, and shrimps. MLCs appear to be interesting candidate allergens. MLCs have been already identified as minor allergens in

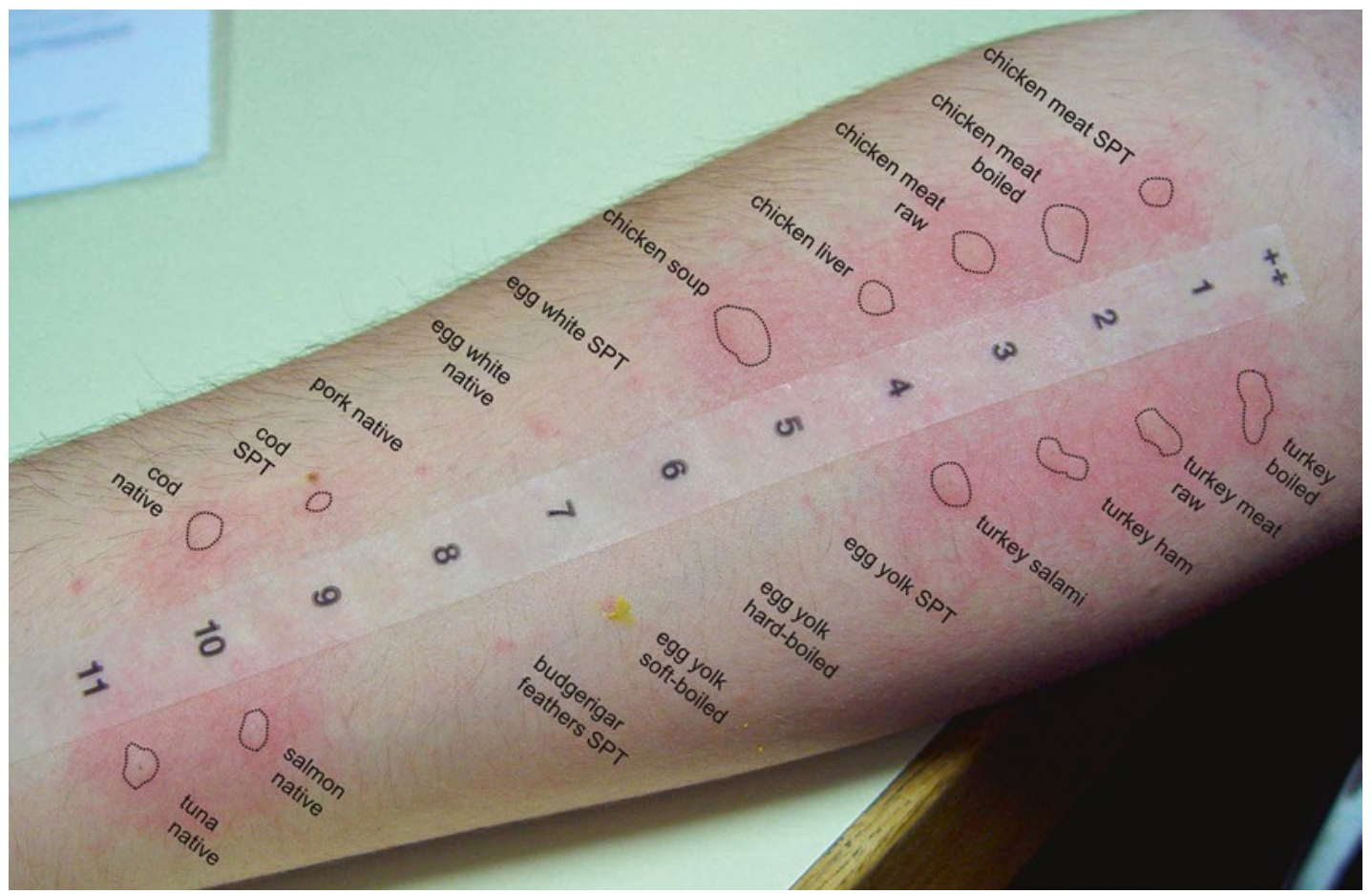

Fig. 5: Prick-to-Prick test with native foods in a patient with chicken meat allergy and concomitant fish intolerance. Specific IgE results: chicken meat $9.73 \mathrm{kU} / \mathrm{l}$, cod $1.47 \mathrm{kU} / \mathrm{l}, \mathrm{rGad}$ c $1<0.35 \mathrm{kU} / \mathrm{l}$. 


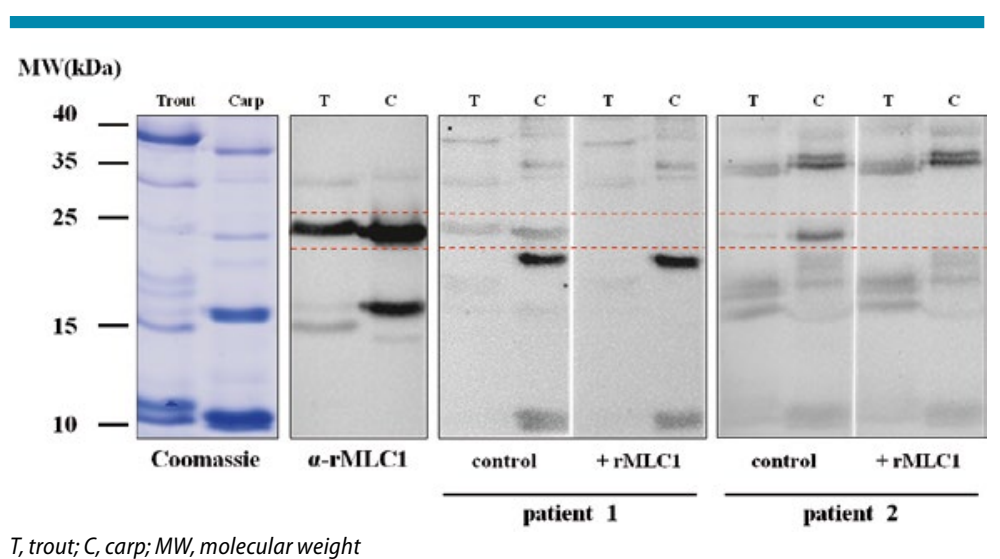

Fig. 6: Demonstration of cross-reactivity between chicken meat myosin light chain (MLC) and fish extracts. A polyclonal rabbit antiserum against recombinant chicken MLC-1 (a-rMLC1) binds to homologous proteins around 16 and $24 \mathrm{kDa}$ in trout and carp extracts. IgE binding of two chicken meat-allergic patients to the $24 \mathrm{kDa}$ fish allergen can be blocked by serum pre-incubation with recombinant chicken meat MLC-1 (rMLC-1).

crustaceans [34, 35], but not so in fishes [33]. Nevertheless, cross-reactions through MLCs may be expected particularly between chicken and fish, since sequence identities are high (63-65\%), whereas the homology between chicken MLC and known shrimp MLCs is only $30 \%$.

In immunoblot inhibition experiments in a limited number of patients we were able to demonstrate that MLC-dependent cross-reactions between chicken meat and fish are possible (Fig. 6), but these observations need to be confirmed in a higher number of patients. Another observation supporting a role of cross-reactive bird and fish MLCs is that a polyclonal rabbit antiserum against recombinant chicken MLC-1 strongly binds to homologous proteins of similar molecular size in trout and carp extracts (Fig. 6). Altogether, our observations provide evidence that simultaneous reactivity with poultry meat, fish and possibly shrimp on the basis of MLCs and/or other still unknown cross-reactive allergens is not uncommon at all and often clinically relevant.

\section{General conclusions}

Serum albumines have been early identified as the responsible allergens in bird-egg syndrome. While cross-sensitization to poultry meat is common in patients with bird-egg syndrome, clinical reactions after meat ingestion appear to be rare because of the heat-lability of serum albumins. Primary poultry meat allergy is mainly seen in adolescents and young adults and regularly associated with moderately severe systemic reactions. The responsible major allergens are heat-resistant low molecular weight proteins some of which have been recently identified as $\alpha$-parvalbumin and myosin light chain. Recent observations considering case histories and serologic data suggest a close relationship of poultry meat allergy with allergy to fish and shellfish presumably based on the presence of cross-reactive homologous allergens in these foods.

\section{Wolfgang Hemmer, PhD \\ Floridsdorf Allergy Centre \\ Franz Jonas Platz 8/6 \\ A-1210 Vienna, Austria \\ E-Mail: hemmer@faz.at}

\section{Förderung}

Diese Arbeit wurde durch den Österreichischen Wissenschaftsfonds (FWF), Grant P 25868-B13, unterstützt.

\section{Conflicts of interest}

The authors declare that there are no conflicts of interests.

\section{Cite this as}

Hemmer W, Klug C, Swoboda I. Update on the bird-egg syndrome and genuine poultry meat allergy. Allergo J Int 2016;25:68-75

DOI: $10.1007 / \mathrm{s} 40629-016-0102-8$

\section{References}

1. Bock SA, Sampson HA, Atkins FM, Zeiger RS, Lehrer S, Sachs $M$, et al. Double blind, placebo controlled food challenge (DBPCFC) as an office procedure: a manual. J Allergy Clin Immunol 1988;82:986-97

2. Sampson HA. Role of immediate food hypersensitivity in the pathogenesis of atopic dermatitis. J Allergy Clin Immunol 1983;71:473-80

3. Hoffman DR, Guenther DM. Occupational allergy to avian proteins presenting as allergy to ingestion of egg yolk. J Allergy Clin Immunol 1988;81:484-7

4. Añibarro Bausela B, Martín Esteban M, Martínez Alzamora F, Pascual Marcos C, Ojeda Casas JA. Egg protein sensitization in patients with bird feather allergy. Allergy 1991;46:614-8

5. Mandallaz MM, de Weck AL, Dahinden CA. Bird-egg syndrome. Cross-reactivity between bird antigens and eggyolk livetins in IgE-mediated hypersensitivity. Int Arch Allergy Appl Immunol 1988;87:143-150

6. Szépfalusi Z, Ebner C, Pandjaitan R, Orlicek F, Scheiner O, Boltz-Nitulescu G, et al. Egg yolk alpha-livetin (chicken serum albumin) is a cross-reactive allergen in the birdegg syndrome. J Allergy Clin Immunol 1994;93:932-42

7. Van Toorenbergen AW, Huijskesheins MIE, Van Wijk RG. Different pattern of IgE binding to chicken egg yolk between patients with inhalant allergy to birds and food-allergic children. Int Arch Allergy Immunol 1994;104:199-203

8. Añíbarro B, García-Ara C, Ojeda JA. Bird-egg syndrome in childhood. J Allergy Clin Immunol 1993;92:628-30

9. Quirce $S$, Marañón $F$, Umpiérrez A, de las Heras $M$, Fernández-Caldas E, Sastre J. Chicken serum albumin (Gal d 5) is a partially heat-labile inhalant and food allergen implicated in the bird-egg syndrome. Allergy 2001;56:754-62 
10. Villas F, Compes E, Fernández-Nieto M, Muñoz MP, Bartolome B, de las Heras M. Bird-egg syndrome caused by Agapornis species (lovebird). J Investig Allergol Clin Immunol 2009;19:71-2

11. Nevot Falcó S, Casas Ramisa R, Lleonart Bellfill R. Bird-egg syndrome in children. Allergol Immunopathol (Madr) 2003;31:161-5

12. Bausela BA, Garcia-Ara MC, Martin Esteban M, Boyano Martinez TB, Diaz Pena JM, Ojeda Casas JA. Peculiarities of egg allergy in children with bird protein sensitization. Ann Allergy Asthma Immunol 1997;78:213-6

13. Cheikh Rouhou S, Bachouch I, Racil H, Chaouch N, Zarrouk M, Salmi L, et al. Anaphylaxis due to chicken meat. Rev Mal Respir 2012;29:98-100

14. Martínez Alonso JC, Domínguez Ortega FJ, Fuentes Gonzalo MJ. Angioedema due to sensitization to chicken meat. Allergol Immunopathol (Madr) 2003;31:50-2

15. Liccardi G, Szepfalusi Z, Noschese P, Nentwich I, D'Amato M, D'Amato G. Allergy to chicken meat without sensitization to egg proteins: A case report. J Allergy Clin Immunol 1997;100:577-9

16. Vila L, Barbarin E, Sanz ML. Chicken meat induces oral allergy syndrome: a case report. Ann Allergy Asthma Immunol 1998;80:195-6

17. Cahen YD, Fritsch R, Wüthrich B. Food allergy with monovalent sensitivity to poultry meat Clin Exp Allergy 1998;28:1026-30

18. Kelso JM, Cockrell GE, Helm RM, Burks AW. Common allergens in avian meats. J Allergy Clin Immunol 1999;104:202-4

19. Zacharisen MC. Severe allergy to chicken meat. WMJ 2006;105:50-2

20. Sokolova A, Costa AC, Santos MC, Bartolomé B, Barbosa MP. Severe allergy to poultry meat without sensitisation to egg proteins with concomitant Leguminosae allergy. Case report. Allergol Immunopathol 2009;37:165-72

21. Kuehn A, Lehners C, Hilger C, Hentges F. Food allergy to chicken meat with IgE reactivity to muscle alpha-parvalbumin. Allergy 2009;64:1557-8

22. Theler B, Brockow K, Ballmer-Weber BK. Clinical presentation and diagnosis of meat allergy in Switzerland and Southern Germany. Swiss Med Wkly 2009;139:264-70

23. Hilger C, Swiontek K, Hentges F, Donnay C, de Blay F, Pauli G. Occupational inhalant allergy to pork followed by food allergy to pork and chicken: sensitization to hemo- globin and serum albumin. Int Arch Allergy Immunol 2010;151:173-8

24. González-Mancebo E, Pastor C, González-de-Olano D, Gandolfo-Cano M, Melendez A, Cuesta J, et al. Identification of allergens in chicken meat allergy. J Investig Allergol Clin Immunol 2011;21:326-7

25. González-de-Olano D, Bartolomé B, Maroto AS, Vivanco F, Pastor-Vargas C. Asthma after chicken consumption due to cross-reactivity between fish and chicken parvalbumin. J Investig Allergol Clin Immunol 2012;22:227-8

26. Barnig C, Hilger C, Muti D, Blaumeiser M, Purohit A, Hentges $F$, et al. Anaphylaxis to vapors of roasting chicken controlled by omalizumab. J Investig Allergol Clin Immunol 2012;22:439-40

27. Can C, Yazicioglu M, Ciplak G. Chicken meat anaphylaxis in a child with no allergies to eggs or feathers. Iran J Pediatr 2014;24:786-7

28. Ayuso R, Lehrer SB, Tanaka L, Ibañez MD, Pascual C, Burks $A W$, et al. IgE antibody response to vertebrate meat proteins including tropomyosin. Ann Allergy Asthma Immunol 1999;83:399-405

29. Polasani R, Melgar L, Reisman RE, Ballow M. Hot dog vapor induced status asthmaticus. Ann Allergy Asthma Immunol 1997;78:35-6

30. Klug C, Hemmer W, Focke M, Wank H, Quirce S, Gaubitzer $E$, Swoboda I. Identification and characterisation of the muscle protein, myosin light chain 1, as a major chicken meat allergen (abstract). Allergy 2015;70(Suppl):in press

31. Crow MT, Olson PS, Stockdale FE. Myosin light-chain expression during avian muscle development. J Cell Biol 1983;96:736-44

32. Restani P, Fiocchi $A$, Beretta $B$, Velonà $T$, Giovannini $M$, Galli CL. Meat Allergy. III. Proteins involved and cross-reactivity between different animal species. J Am Coll Nutr 1997;16:383-9

33. Kuehn A, Swoboda I, Arumugam K, Hilger C, Hentges F. Fish allergens at a glance: variable allergenicity of parvalbumins, the major fish allergens. Front Immunol 2014;5:179

34. Ayuso R, Grishina G, Bardina L, Carrillo T, Blanco C, Ibáñez $M D$, et al. Myosin light chain is a novel shrimp allergen, Lit v 3. J Allergy Clin Immunol 2008;122:795-802

35. Bauermeister K, Wangorsch A, Garoffo LP, Reuter A, Conti A, Taylor SL et al. Generation of a comprehensive panel of crustacean allergens from the North Sea Shrimp Crangon crangon. Mol Immunol 2011;48:1983-92 